Nuclear Instruments and Methods 179 (1981) 487-493

(ㅇ) North-Holland Publishing Company

\title{
HOLOGRAPHIC PHOTOGRAPHY OF BUBBLE CHAMBER TRACKS A FEASIBILITY TEST
}

\author{
M DYKES, P LECOQ, D GUSEWELL, A HERVÉ, H WENNINGER \\ CERN, European Organtzation for Nuclear Research, Geneva, Switzerland
}

\author{
H ROYER \\ Institut Franco-Allemand de St Louts, France \\ B HAHN, E HUGENTOBLER, E RAMSEYER \\ Unversitat Bern, Bern, Switzerland
}

and

\author{
M BORATAV \\ Unwersite Curte, Parts, France
}

Recerved 15 August 1980

The use of holography should permit the improvement of optical resolution in bubble chambers without the loss of depth of field inherent in conventional photography, and should also permit the use of much more intense particle beams in bubble chambers Holographic techniques have been applied to a small heavy liquid bubble chamber in the conditions of a particle physics experiment and a resolution of $8 \mu \mathrm{m}$ over a depth of field of some $10 \mathrm{~cm}$ has been obtained, yielding a reconstructed image of very high quality $6 \mu \mathrm{m}$ bubbles have also been reconstructed but with inferior contrast and quality Various tests have been performed in order to determine some limitations of the method

\section{Introduction}

Recently, in the field of high energy physics, there has been a strong revival of interest in vertex detectors capable of examining the interaction region with very high spatial resolution, combined with downstream spectrometers devoted to track analysis In such vertex detectors it is possible to observe directly the production and subsequent decay of short-lived particles, to detect short recoll tracks, and to measure track ionisation over short distances Current theoretical models predict the production of particles having life-times in the range $10^{-12} \mathrm{~s}$ to $10^{-15} \mathrm{~s}$, such as the new hadrons of super-symmetric theories [1], the $\tau$-lepton [2] and the charmed particles [3] Direct observation of the decay of such particles, requiring optical resolution down to a few microns, can be used as a clean, background-free signature to study their production mechanism Two recent experiments carried out at CERN with rapid cycling bubble chambers $[4,5]$ showed that with devices using conventional optics it is possible to achieve resolutions corresponding to approximately $30 \mu \mathrm{m}$ bubble diameter
However, such a resolution, very favourable for the $10^{-12}-10^{-13} \mathrm{~s}$ range, is marginal for particles decaying in less than $10^{-13} \mathrm{~s}$, as might be the case, for example, with the $\mathrm{D}^{0}$

The limited resolution of these bubble chambers is inherent in the conventional photographic methods used for data recording A minimum optical depth of field of a few millimeters is required to keep in focus secondary tracks diverging from the interaction point at even small angles This requirement limits the lens aperture to a value corresponding to a resolution limit of a few tens of micrometers Improvement of resolution is only possible by sacrifice of depth of field This limited depth of field imposes also a limit on the number of incident particles per picture and hence on the sensitivity of the experiment

It was pointed out some years ago [6] that the compromise between resolution and depth of field could be avorded by the use of holographic techniques in bubble chambers The idea has been revived in a recent paper [7] and supported by some encouraging tests at CERN and Rutherford Laboratory $[8,9]$

The aim of the present experiment was to check 
the feasibility of recording bubble chamber tracks on a hologram and to explore, under real experimental conditions, the practical limitations on such parameters as resolution, depth of field, bubble densities, maximum quantity of information per hologram, etc

\section{Experımental set-up}

\section{The bubble chamber}

The small heavy liquid bubble chamber BIBC (Bern Infinitesimal Bubble Chamber), recently used in a search for short-lived particles at CERN, was very suitable for holography tests This chamber was designed to produce high bubble density tracks to be
Table 1

Characteristics of BIBC

\section{Chamber liquid}

Operating temperature $T$

$\mathrm{C}_{3} \mathrm{~F}_{8}$ (freon)

Vapour pressure at $T$

Liquid density at $T$

Refractive index

Bubble density for minımum 1onızıng particles (determined by gap distribution for $30 \mu \mathrm{m}$ bubbles)

Expansion rate

$425^{\circ} \mathrm{C}$

$139 \mathrm{bar}$

$121 \mathrm{~g} / \mathrm{cm}^{3}$

12

$290 / \mathrm{cm}$ up to $5 \mathrm{~Hz}$

photographed by a conventional high resolution optical system, a complete description will be given elsewhere [10]

Some characteristics of BIBC are summarized in

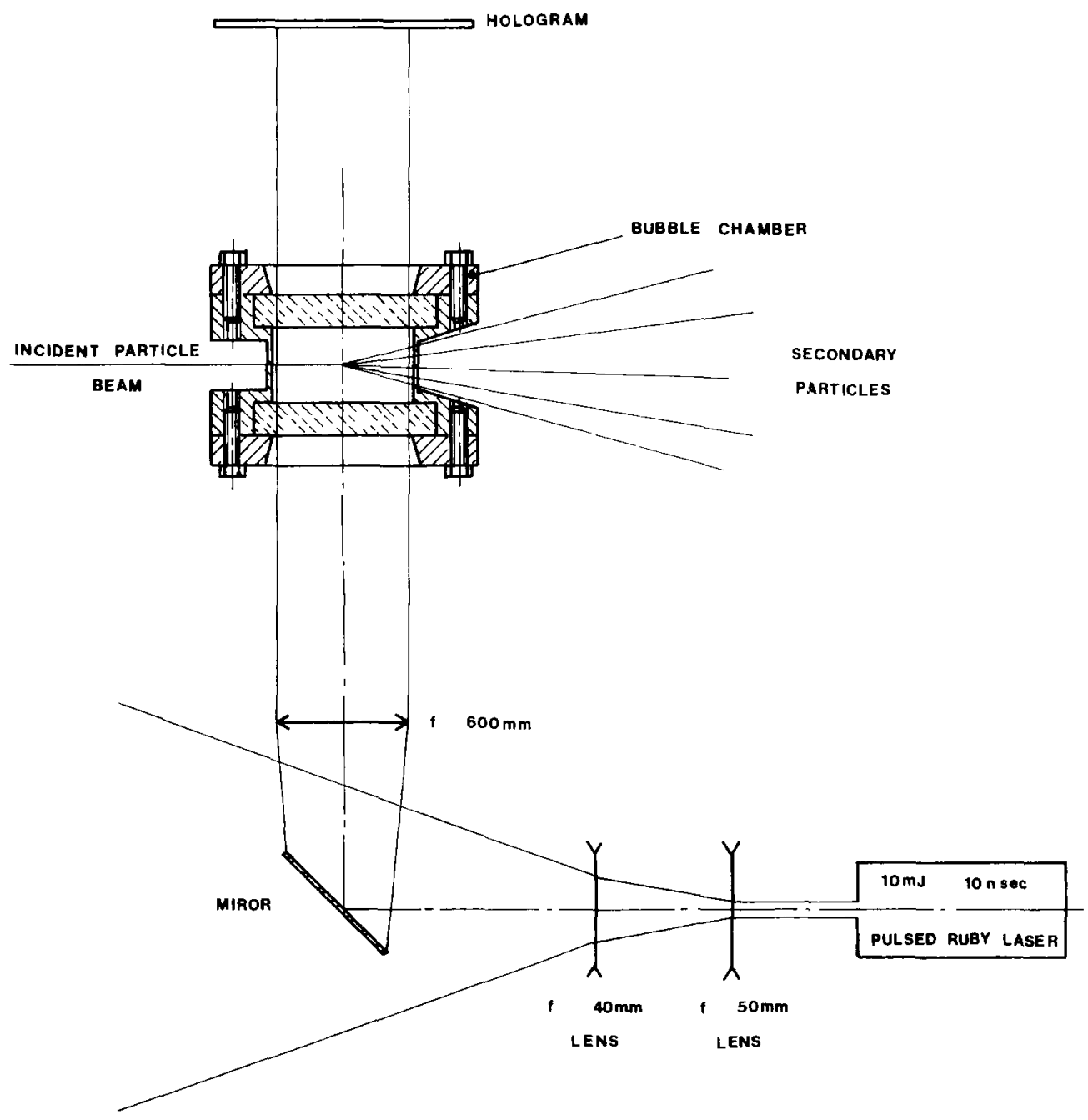

Fig 1 Experimental arrangement 
table 1 The visible volume is cylindrical with a diameter of $65 \mathrm{~mm}$ and a depth of $35 \mathrm{~mm}$ between the two windows made of optical quality BK7 glass The outer window faces are coated with a single layer "Iralın" antıreflection coatıng

\section{The hologram and the laser}

The design of BIBC allows the use of the simplest form of hologram, the "in-line" type (fig 1)

The monomode, Q-switched ruby laser delivers single light pulses of $10 \mathrm{~mJ}$ in $10 \mathrm{~ns}$ of wavelength $694 \mathrm{~nm}$ This light pulse was synchronized with the particle beam and with the bubble chamber expansion system The light beam is expanded to the dimensions of the object field and passes through the bubble chamber onto a holographic plate or film A small part of the incident light is diffracted by the bubbles and interference between the diffused and the non-diffused waves produces fringes which are recorded by the emulsion

This arrangement has important advantages It is very simple and needs very few adjustments The image is free from field aberrations and its quality under good experimental conditions is limited only by the diffraction effect For the special case of small objects (far field conditions) there is negligible interference between the real and the virtual images On the other hand, since the reference beam travels through the object field, the image quality is sensitive to turbulence in the bubble chamber hquid as well as to the total number of bubbles present in the chamber [11]

In a physics experiment a ruby laser would not be satisfactory because of its limited pulse repetition rate, imposed by problems of cooling the laser rod However, suitable neodymum-YAG or dye lasers are commercially avallable

\section{The particle beam}

Durnng the tests BIBC was exposed to an unseparated beam of negative particles derived from the CERN $400 \mathrm{GeV}$ Proton Synchrotron The particles were mainly $\pi^{-}$with energies of $15 \mathrm{GeV}$ in the early tests and $140 \mathrm{GeV}$ later on The "fast beam ejection" system, which delivers particles in well-defined bunches some $24 \mu$ s long, was used to ensure that all the bubbles in all the tracks photographed on a given hologram were of simlar size The bubble chamber expansion system was synchronized to the beam arrival tıme, and an electronic control system fired the laser by "Q-switchung" at the appropriate time to form the hologram of the bubble chamber tracks

\section{The tests}

Holograms were made both on glass plates and on $170 \mu \mathrm{m}$ polyester based film, both coated with AgfaGevaert 10E75 emulsion The plates had an antihalation layer and were fixed on a plate holder $\sim 10 \mathrm{~cm}$ from the middle of the chamber The film had no antihalation layer and was sucked down either on a glass film back $10 \mathrm{~cm}$ from the beam line or on a metallic capstan $18 \mathrm{~cm}$ away The theoretical limit of resolution is given by the Rayleigh formula

resolution $=244 \lambda x / D$ at one Rayleıght limit , where $\lambda$ is the laser wavelength $=694 \mathrm{~nm}, x$ is the object-emulsion distance $=10 \mathrm{~cm}$ or $18 \mathrm{~cm}, D$ is the hologram drameter $=6 \mathrm{~cm}$, which yields about $3 \mu \mathrm{m}$ and about $5 \mu \mathrm{m}$ respectively for the two experimental conditions

Around $1 \mu \mathrm{m}$ must be added to these theoretical values to take into account the spherical aberration of the glass window Moreover the effective hologram diameter was sometimes less than $6 \mathrm{~cm}$ because of a misalignment of the optical system, as is clear in fig 11

We recorded tracks of different sized bubbles, by varying the time interval between the passage of the 1onizing beam and the laser light pulse We also varied the number of tracks in the chamber between ten and approximately 150

\section{Results}

For the reconstruction and analysis of holograms we used a $4 \mathrm{~mW}$ contınuous helium-neon laser of wavelength $633 \mathrm{~nm}$, with a telescope incorporating a $10 \mu \mathrm{m}$ diameter spatial filter, y1elding a clean $7 \mathrm{~cm}$ drameter reconstruction beam The real image of the hologram was then examined with a microscope mounted on a movable stage, coupled with a television camera (Philips LDH 26) Depending on the microscope objective the magnification on the telev1sion monitor screen was either $X 120$ or $X 500$ (fig 2)

Holograms on glass plates allow the reconstruction of $6 \mu \mathrm{m}$ diameter bubbles with high contrast and high quality throughout the full depth of the chamber $(35 \mathrm{~cm})$ Dust particles on the outer surfaces of the 


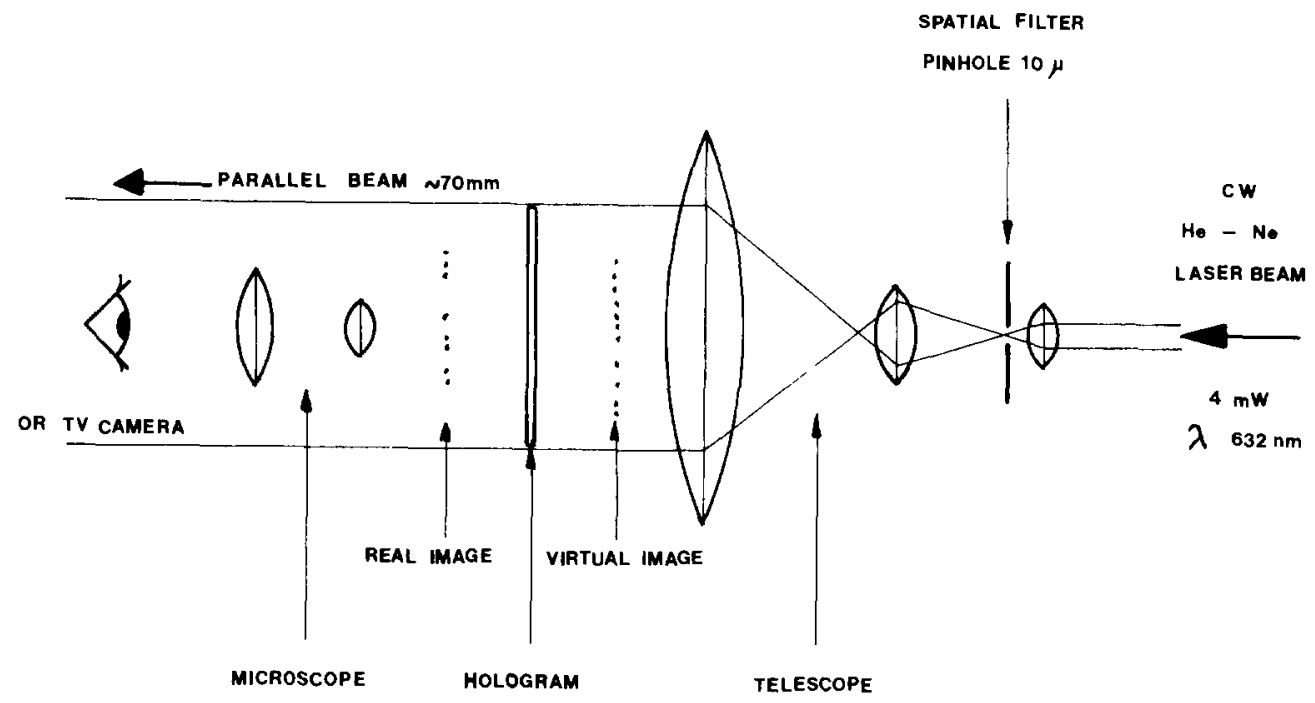

Fig 2 Reconstruction set-up
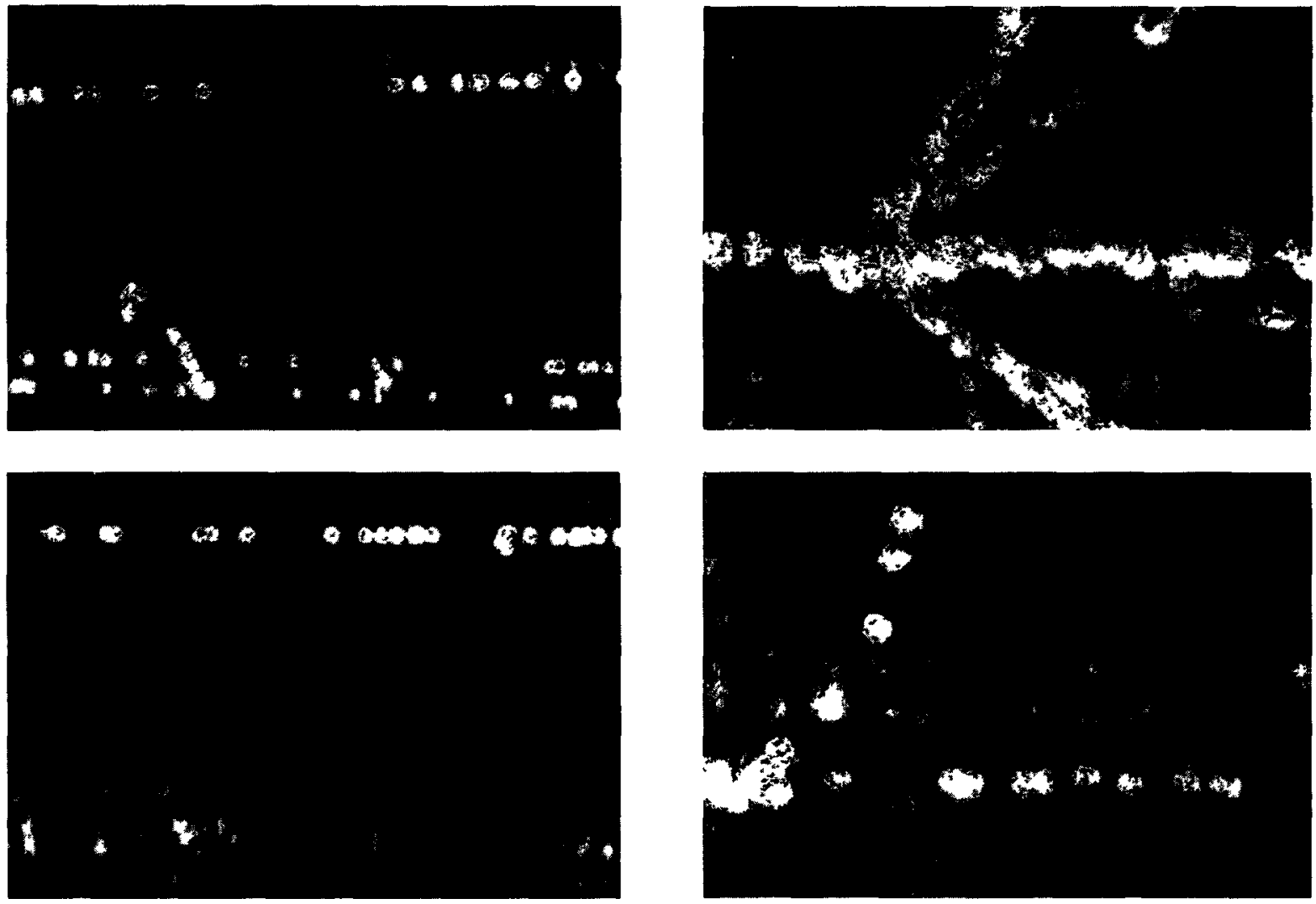

Figs 3 and 4 The two pictures cover the same area of the reconstructed image for two different positions of the microscope The tracks at the top of each picture are exactly on the same optical axis, but separated in depth by $3 \mathrm{~mm}$ The reconstructed bubble size is approximately $8 \mu \mathrm{m}$

Fig 5 About $40 \mu$ s delay between the particle trigger and the laser flash The bubble size is $30 \mu \mathrm{m}$

Fig 6 About $30 \mu$ s delay between the particle trigger and the laser flash The bubble size is $25 \mu \mathrm{m}$ 

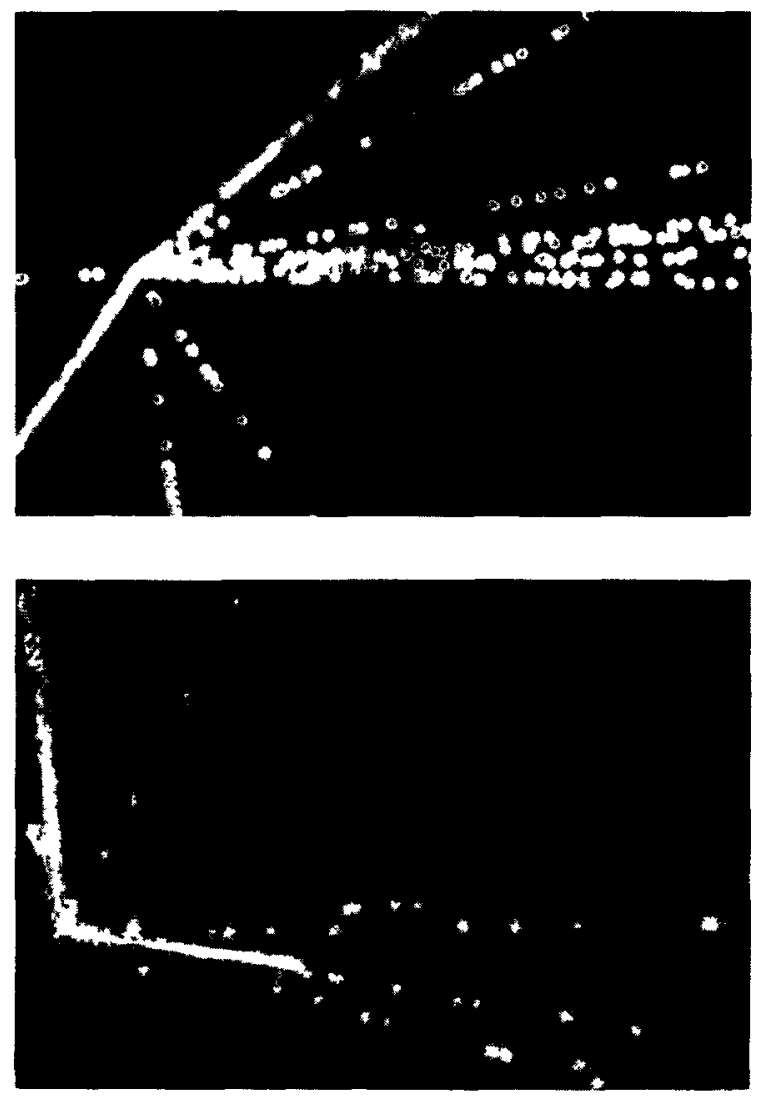

Fig 7 About $7 \mu$ s delay between the particle trigger and the laser flash The bubble size is $8 \mu \mathrm{m}$

Fig 8 About $2 \mu$ s delay between the particle trigger and the laser flash The bubble size is $6 \mu \mathrm{m}$

windows and the two $10 \mu \mathrm{m}$ wires mounted in front of and behind the chamber are also reconstructed with the same quality, showing that the depth of field is at least $92 \mathrm{~cm}$, it is probably much more It is possible to exploit this large depth of field even for tracks on the same optical axis (that is, with one track precisely behind the other) Figs 3 and 4 show two reconstructed tracks formed of $8 \mu \mathrm{m}$ bubbles lying on the same optical axis and separated in depth by $3 \mathrm{~mm}$ as judged by the two corresponding focusing positions of the microscope

By varying the time delay between the passage of the particle beam and the laser flash it was possible to photograph bubbles of different sizes Due to some jitter in the laser Q-switch, this time interval is not precisely known and the times given are probably not very accurate, nevertheless, figs $5-8$ show reconstructed bubbles with diameters from $30 \mu \mathrm{m}$ to $6 \mu \mathrm{m}$
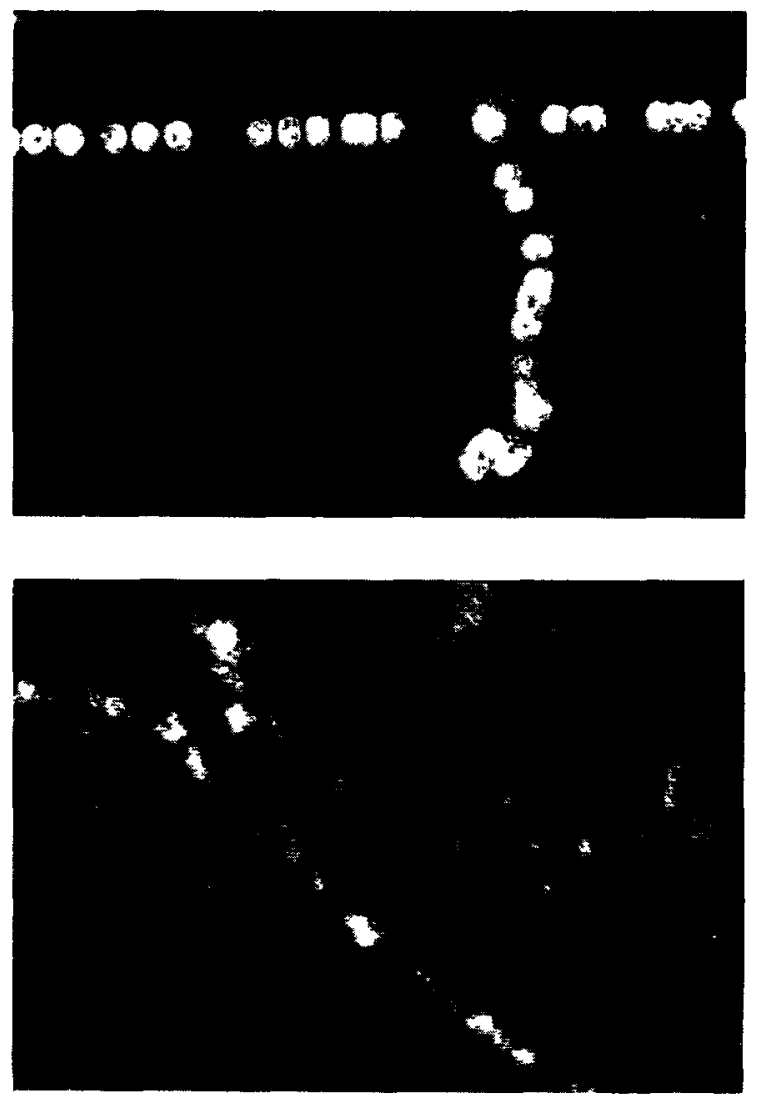

Fig 9 About 1000 bubbles/cm Chamber temperature $435^{\circ} \mathrm{C}$ Bubble size $8 \mu \mathrm{m}$. The length of this track element 1s $220 \mu \mathrm{m}$.

F1g 10160 tracks with some 300 bubbles/cm were counted on this hologram Seven tracks cross the field of the picture (approximately $1 \mathrm{~mm}^{2}$ ) Only one of them is in focus

It is important to note that the contrast is very high even for small bubbles, although for the $6 \mu \mathrm{m}$ bubbles the real image of the bubble is no longer visible, but rather the diffraction spot This is to be expected, as we are approaching the theoretical limiting resolution

The mean value of bubble density for normal chamber conditions $\left(T=425^{\circ} \mathrm{C}\right)$ is 300 bubbles $/ \mathrm{cm}$ for minımum lonizing particles and $8 \mu \mathrm{m}$ bubbles On increasing the bubble chamber temperature to $435^{\circ} \mathrm{C}$, the density increased to 400 bubbles $/ \mathrm{cm}$ For slow particles the ionization can be much higher and the very high resolution makes it possible to count up to 1000 bubbles/cm (fig 9)

Because of the large information storage capability and high resolution of holograms it is possible to 


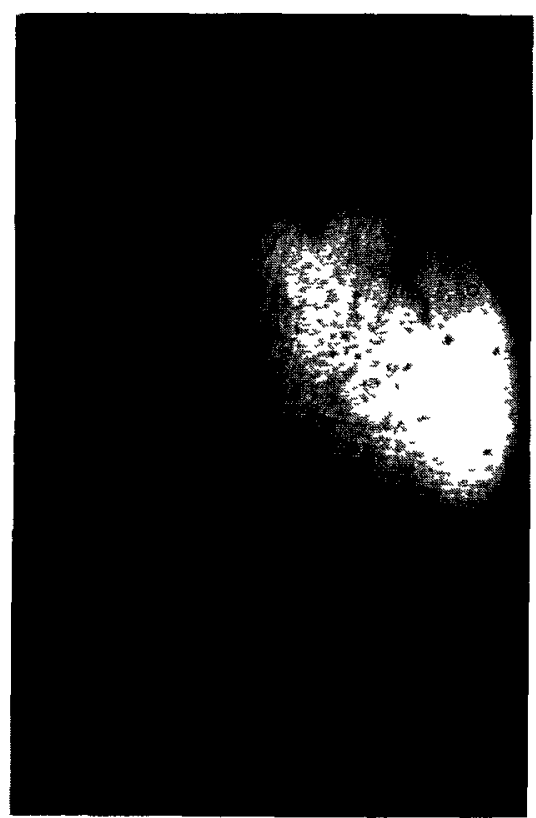

Fig 11 Contact print of a hologram with normal conditions single shot of BIBC

accept more tracks per expansion in a holographic than in a conventional bubble chamber [7] Fig 10 shows reconstructed tracks from a hologram where 160 tracks were counted in the chamber Seven tracks traverse the field of the picture $\left(1 \mathrm{~mm}^{2}\right)$ at different depths, and the track in focus is still clearly visible although the background is more pronounced than with a lower track density According to the results it seems to us that a maximum of 200-250 tracks per hologram is a realistic figure in a BIBC-shaped chamber

In order to study the influence of turbulence on image quality, we expanded the chamber at a frequency of $5 \mathrm{~Hz}$ for $1 \mathrm{~s}$ before picture taking Comparison of figs 11 and 12 show that a strong macroscopic turbulence appeared Fig 13 shows that the images are not completely destroyed by thus turbulence and that it is still possible to follow tracks through the whole chamber although the quality of the picture is reduced, as is obvious from comparison with fig 9

Tests were also made on film (as opposed to glass plates) in two configurations

- At $10 \mathrm{~cm}$ distance from the middle plane of the bubble chamber, the film (Agfa-Gevaert 10E75 emulsion on a thick $170 \mu \mathrm{m}$ polyester base) was sucked down on a glass film back Newton's rings are

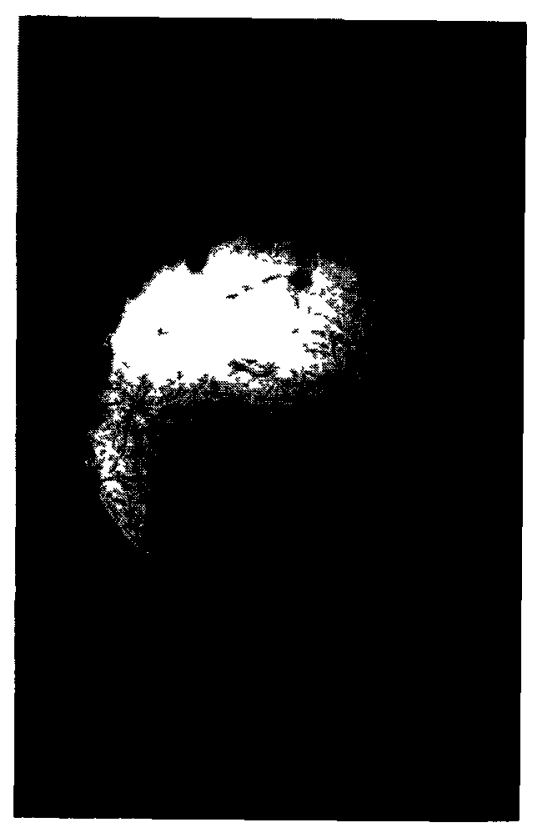

Fig 12 Contact print of a hologram when the chamber is operated at $5 \mathrm{~Hz}$ The shadow effect due to turbulence is clearly visıble

clearly visible on the hologram, which indicate that the flatness of the emulsion was not perfect, and that we suffered from having no antihalation layer Nevertheless, the quality of the pictures is rather good as is shown in fig 14 and is comparable with the quality using glass plates

- At $18 \mathrm{~cm}$ distance, the film was sucked down on a metallic capstan In this case, the absence of an ant1halation layer was evident, the structure of the capstan clearly appearıng on the hologram It must be remembered that the distance film-object was rather

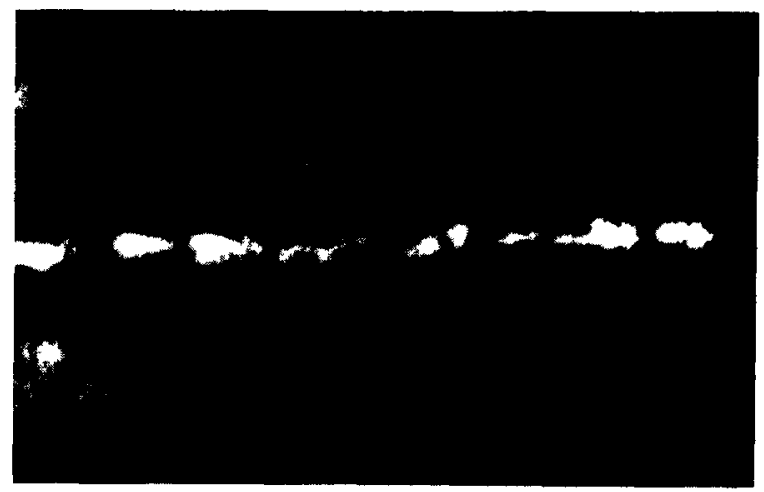

Fig 13 Track reconstructed trom the hologram shown in fig 12 The track is still clearly visible although the shape of the bubbles is lost 


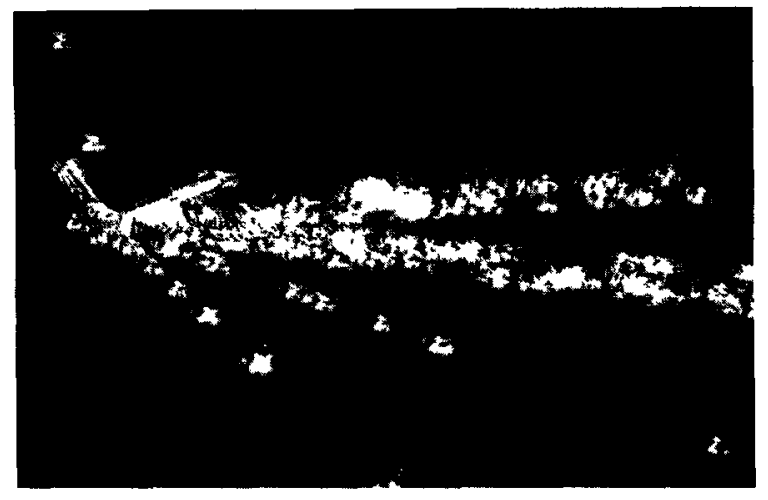

Fig 14 Event reconstructed from a hologram taken on a film sucked down on a glass film back at $10 \mathrm{~cm}$ from the BIBC centre Bubble size $8 \mu \mathrm{m}$ The relatively bad quality is mainly due to the absence of an antihalation layer

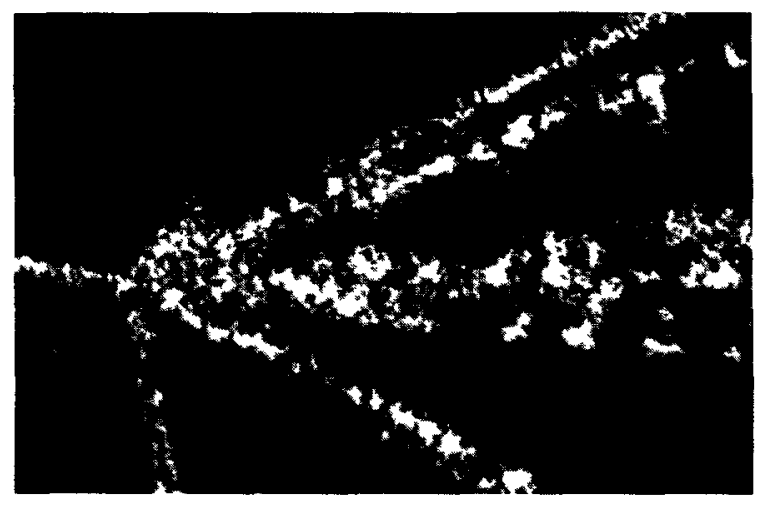

Tig 15 Event reconstructed from a hologram taken on a film sucked down on a metallic capstan at $18 \mathrm{~cm}$ from the BIBC centre Bubble size $8 \mu \mathrm{m}$ The relatively bad quality is due to the absence of an antuhalation layer combined with a reduction of the optical aperture as compared to the previous picture

large, which limits the resolution One example of an event with $8 \mu \mathrm{m}$ bubbles is shown in fig 15

\section{Conclusion}

The test has demonstrated quite conclusively that in a small heavy liquid bubble chamber microscopic particle tracks can be recorded on holograms and that with depths of field in excess of $10 \mathrm{~cm}$, bubbles down to $8 \mu \mathrm{m}$ in diameter can be recorded and reconstructed with excellent contrast Film was used in addition to glass plate Good results were achieved, although it is clear that a careful camera design will be necessary for high speed data taking at nearly glass plate quality Very useful practical information has been gathered concerning the effect of turbulence in the chamber and the effects on optical background of the simultaneous presence in the chamber of up to 150 tracks It has also been possible to form at least some impressions of the problems of scanning and measurnng reconstructed holograms Early tests have shown for instance that by 1 lluminating the hologram with divergent coherent laser light, it is possible to project onto a screen the whole image with a magnification between 10 and 20 Good image quality is obtained over the whole field and the depth of field is about $1 \mathrm{~cm}$ These conditions are very suitable for scanning Monochromatic light given by a filtered mercury-vapour lamp passing through a $250 \mu \mathrm{m}$ pinhole allows also image reconstruction with quite acceptable quality

Although the problems of liquid hydrogen are somewhat different from those of heavy liquid bubble chambers (liquid properties, slower bubble growth, lower bubble density, more windows, etc), we think that hydrogen bubble chambers are equally suitable for use with holography We hope that our results are sufficiently encouraging to stimulate interest in proposals for physics experiments using small bubble chamber "vertex detectors" with holographic methods

The authors thank A Minten and L Montanet (CERN) and the director of the Institut St Lous for support, E Chiaver and $J$ May for providing the partıcle beam, the BEBC and EHS groups at CERN, and $G$ Vanhomwegen of Brussels University and $H$ Tritsch of the Institut Franco-Allemand in St Louls for invaluable help during the settıng up and carrying out of the experiment We are also grateful to $\mathrm{H}$ Anders and $\mathrm{K}$ Geissler for assistance and helpful discussions

\section{References}

[1] G R Farrar and P Fayet, Phys Lett 76B (1978) 575

[2] G J Feldman, Comments Nucl Part Phys 9 (1979) 23

[3] J L Rosner, Invited Talk at Workshop on Charm production and lifetımes, Bartol Research Foundation, University of Delaware (1978).

[4] W Allison et al, CERN/EP 8049 (April 1980) (to be published in Phys Lett B)

[5] A Badertscher et al, BIBC Proposal, CERN/SPSC 79-81

[6] W T Welford, Appl Phys 5 (1966) 872

[7] F R Eisler, Nucl Instr and Meth 163 (1979) 105

[8] CERN Courier 20-4, Holography for bubble chambers (June 1980)

[9] CERN/EP/EHS/PH 80-2, Second Vezelay Workshop on EHS High resolution vertex detectors

[10] B Hahn, E Hugentobler and E Ramseyer, BIBC description (to be published)

[11] H Royer, Nouv, Rev Optıque 5 (1974) 87 